\title{
Team learning: building shared mental models
}

\author{
Piet Van den Bossche • Wim Gijselaers • Mien Segers • \\ Geert Woltjer • Paul Kirschner
}

Received: 4 December 2008/ Accepted: 2 March 2010/Published online: 17 March 2010

(C) The Author(s) 2010. This article is published with open access at Springerlink.com

\begin{abstract}
To gain insight in the social processes that underlie knowledge sharing in teams, this article questions which team learning behaviors lead to the construction of a shared mental model. Additionally, it explores how the development of shared mental models mediates the relation between team learning behaviors and team effectiveness. Analyses were performed on student-teams engaged in a business simulation game. The measurement of shared mental models was based on cognitive mapping techniques. The results indicate that a team learning perspective provides insight in how people share knowledge. Particularly the team learning behaviors identified as co-construction and constructive conflict are related to the development of shared mental models. In addition, a shared mental model of the task environment in a team leads to improved performance. This underscores the importance of developing shared cognition in teamwork.
\end{abstract}

Keywords Team learning - Shared mental model $\cdot$ Shared cognition · Cognitive mapping

\section{Introduction}

Teams are increasingly being employed to discuss and manage complex problems. Organizations rely on these teams to deal with a fast-changing and highly competitive

P. Van den Bossche $(\bowtie) \cdot$ W. Gijselaers $\cdot$ M. Segers

Department of Educational Research \& Development, School of Business \& Economics,

University of Maastricht, PO Box 616, 6200 MD Maastricht, The Netherlands

e-mail: Piet.vandenBossche@maastrichtuniversity.nl

P. Van den Bossche

University of Antwerp, Venusstraat 35, Antwerp, Belgium

G. Woltjer

LEI, Wageningen UR, The Hague, The Netherlands

P. Kirschner

Open University of the Netherlands, Heerlen, The Netherlands 
environment. Also educational environments see benefits in the implementation of learning environments that have a crucial team learning component.

Both the working teams in organizations as the learning groups in schools are confronted with the same issues; "they are faced with challenges of establishing common frames of reference, resolving discrepancies in understanding, negotiating issues of individual and collective action, and coming to joint understanding" (Barron 2000, pp. 403-404). The essence of collaboration is hereby a process of building and maintaining a shared conception of a problem (Dillenbourg and Traum 2006; Roschelle 1992). The collaborative task demands of teams to create a common ground, a common representation that could serve as a touchstone for coordinating the members' different perspectives on the problem at hand (Schwartz 1995). The important role of this shared cognition in teamwork is acknowledged by both the learning sciences and organization sciences (Akkerman et al. 2007). Research in learning sciences refer to the concepts of common ground and knowledge convergence, while the concept of shared mental models is proposed by organizational sciences (e.g., Klimoski and Mohammed 1994). These concepts reflect the need to study group learning as truly collaborative (Crook 1998; Akkerman et al. 2007); an individual approach would not fully grasp the phenomenon of group-work and group-learning (Thompson and Fine 1999; Stahl 2006). In trying to grasp and understand this collaborative effort, research interests focus on the ways groups are creating meaning and are acting upon collectively developed cognition (Thompson 1998). From this perspective, learning at team-level can be considered as the development of shared cognitions.

As Langfield-Smith (1992) has argued, to understand how collective knowledge structures are formed, it is a basic requirement that one must understand the interaction between cognition and social processes. Research on collaborative learning requires insight into the sociocognitive processes through which a shared conception is built. Insights needs to be gained in the conversational patterns at the group level, instantiating the sociocognitive processes that contribute to the development of shared cognition. These can be considered as the learning behaviors of a team. However, only few studies on collaborative learning have examined how groups of people create or develop shared cognition. This research has confirmed the importance of interaction processes (Jeong and Chi 2007) and is only starting to explore the discourse processes leading to shared cognition (Fischer and Mandl 2005; Beers et al. 2007).

The goal of this study was to link discourse patterns in interaction to the development of shared cognition, based on an elaborated conceptual framework as a guide for defining relevant team learning behavior (Van den Bossche et al. 2006). In addition, the relation between shared cognition in a team and team performance was questioned. By doing so, it shows the importance of the development of shared cognition and underlines the role of team learning behaviors.

In framing learning at team-level, this research draws upon insights from the learning sciences and organizational sciences, as both research strands have complementary insights regarding the development of group cognitions. Moreover, the central methodology for assessing shared cognition of the teams is heavily based upon the extended experience of measuring cognition at group-level in organizational sciences, since in the learning sciences only few studies have tried to measuring shared cognition directly (Jeong and Chi 2007). The following paragraphs elaborate the contribution of the different research strands to the model underlying this study as presented in Fig. 1. 


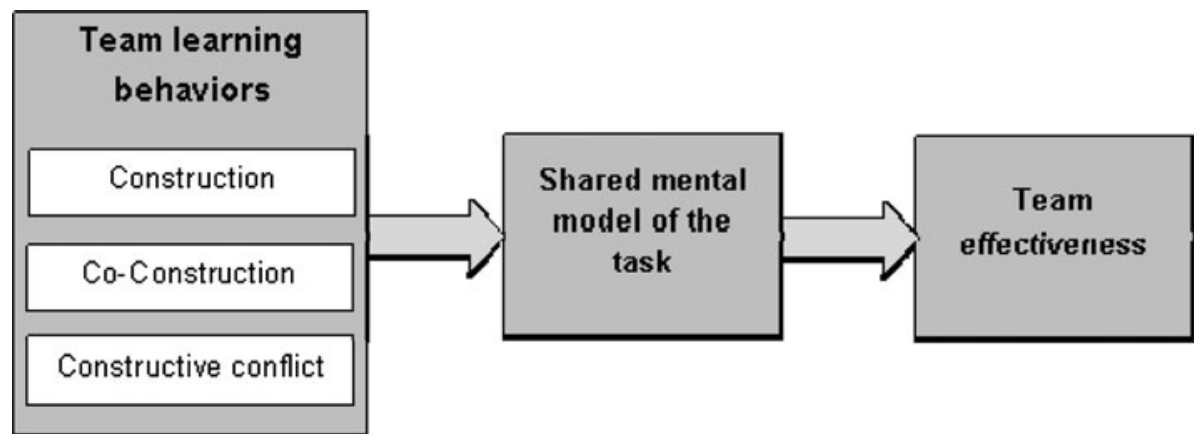

Fig. 1 Conceptual model of this study

\section{Team learning behaviors and shared cognition}

Shared mental models

Cognitive psychology has focused on the way individuals make sense of their environment through 'knowledge structures', conceptualized by Johnson-Laird (1983) as mental models, perceived of as internal representations of (aspects of) the environment that provide a conceptual framework for describing, explaining and predicting future system states (Rouse and Morris 1986). Klimoski and Mohammed (1994) used this understanding of individual sense-making to conceptualize cognition as a group-level phenomenon. Shared mental models refer to the overlapping mental representation of knowledge by members of a team.

Dillenbourg and Traum (2006) have pointed out that the idea of common ground, which is as concept frequently used in the learning sciences, is addressed at different scales: from psycholinguistics at the microlevel to socio-cultural psychology at the macro level. Shared mental models refer to a conceptualization at meso-level, in which there is a focus on conceptual development in small groups solving problems. We chose to use the concept of shared mental model as this does not entail this conceptual confusion with regard to the level of analysis.

Shared mental models can refer to shared representations of tasks, equipment, working relationships and situations (Mohammed and Dumville 2001). It is stated that probably all of these types of knowledge need to be shared in effective teams. Although different researchers have different interpretations (and operationalizations) of shared mental models (for an overview see Akkerman et al. 2007), their research has yielded some insights in shared mental models and their crucial role in team performance. For example, Mathieu et al. (2000) tested the impact of teammates' mental model sharedness on performance, using undergraduate teams completing a series of missions on a PC-based flight simulator. The results indicated that sharedness of task mental models related positively to subsequent team processes and performance. This study was replicated in a more recent laboratory study of Mathieu et al. (2005), showing that task-work mental model similarity was significantly related to team performance. These kinds of results have supported the theoretical proposition that relates effective team performance with the existence of shared mental models.

Given the focus of the present study on how teams come to grasp a collaborative task, we address the role of shared mental models of the task since we are interested in how teams 
come to a shared interpretation of their task environment. Especially in the context of complex task, where the sharing of different perspectives is necessary for successful performance, shared mental models of the task are of significant importance. Task models describe and organize knowledge about how the task is accomplished in terms of procedures, task strategies, likely contingencies or problems, environmental constraints and task component relationships (Cannon-Bowers et al. 1993). Therefore, shared mental model is defined, based on the definition given by Klimoski and Mohammed (1994), as team members' overlapping mental representation of key elements of the team's task environment.

The development of shared mental models

The growing acknowledgement of and insight in cognition at group-level, raises the question on how group cognitions develop. In order for teams to achieve a shared mental representation of the key elements of the task environment, changes in the knowledge of team members occur (Mohammed and Dumville 2001). Mohammed and Dumville stress the significant role of team learning, defined as the development, modification and reinforcement of mental models through processes of group interaction.

This is concurrent with past theorizing of organizational and team researchers, stating that interacting individuals develop similar understandings and interpretations of events (e.g., Rentsch 1990; Walsh et al. 1988). Walsh and colleagues indicated that indirect evidence within team research showed that interaction between team members is a primary cause of mental model agreement. A case in point is the research of Rentsch and Klimoski (2001) that questioned the relation between team size and shared mental models. Team size was taken as a rough estimate of team member interaction opportunity. Their results showed that team size was negatively related to the sharedness of the mental models: larger teams faced a lower likelihood of sharing mental models. More recent research of Jeong and Chi (2007) has confirmed this by establishing a relation between amount of interaction and the development of common knowledge. However, not much is known about the specific discourse patterns that give rise to shared mental models. Research on collaborative learning has focussed on how characteristics of the interaction (discourse practices) interact with knowledge-building processes (Barron 2000). Exemplary for this strand of research looking for patterns of interaction is the work on help-related behaviour in cooperative groups (Webb 1991). In this research, interactions were described by assessing how elaborated the help was which was provided by group members. One of the findings was that the explainers' problem-solving performance benefits from giving elaborated explanation and not from giving non-elaborated help. This stream of work analyzes group work in terms of speech act catalogues and interprets these in terms of impact on individual psychological functioning (Crook 1998; Dillenbourg et al. 1996). The focus on individual performance is logical because one is interested in individual development (Barron 2000). However, within the perspective that successful collaboration requires shared mental models, this view is limited (Barron 2000).

But little studies in the learning sciences have directly measured shared cognition and explored discourse patterns that underlie the development. Fischer and Mandl (2005) present some tentative indicators of how discourse may be related to shared knowledge based on the analysis of a few teamwork cases. These cases revealed that dyads with high shared knowledge display more complex discourse patterns, which show that learners work with a joint focus of attention, transactively respond to their partner's contribution in a manner of flexible co-construction, in the sense of building on what the other contributed before (Fischer and Mandl). 
Also Jeong and Chi (2007) were able to trace back the development of shared knowledge in an analysis of two cases. Moreover, they point out that assessing knowledge convergence solely based on the conversation could lead to an overestimation of shared cognition. The content of the interaction between collaborators is not always encoded and processed sufficiently to become part of the representation. It seems often not sufficient to simply pay attention and acknowledge a contribution; an active effort to explain and integrate the contribution in the existing representation is needed. If one fails to fully process the content of a contribution, this information is not integrated within the representation and remains unshared (Jeong and Chi).

The current research contributes by identifying the kind of interactions that can be considered as team learning behavior leading to the development of shared mental models. It starts from a conceptual framework on team learning to identify the relevant behaviors.

\section{Unraveling team learning behaviors}

To determine the interactions, that is the patterns in discourse, that can be considered as team learning behavior, we make use of the concepts of construction, co-construction and constructive conflict, building on research in the learning sciences (e.g., Dillenbourg et al. 1996; Alpay et al. 1998; Dillenbourg and Traum 2006) and branches of linguistic research on models of conversation, discourse and dialogue (Baker 1995, 1999; Edmondson 1981; Roulet 1992). These two disciplines provide a framework on interactions constituting team learning (Dillenbourg et al.) and note that achieving a shared mental model presupposes joint understanding (Baker 1995). It is, however, not only a matter of understanding each other's representation (mutual understanding), but also of accepting and incorporating each other's ways of seeing (mutual agreement) (Alpay et al. 1998; Dillenbourg and Traum 2006). In reaching mutual understanding and agreement, the following processes are crucial. First, meaning or understanding needs to be (co-)constructed. This is not done through simple accumulation of the contributions of individuals, because these contributions 'build on' previous ones. Second, agreement needs to be established about the proposed solution (Baker 1995). The role of conflict, as the process resulting from differences in point of view, is highly relevant here (De Dreu and Weingart 2003). Previous research confirmed the value of these socio-cognitive processes in understanding team learning behavior in collaborative learning environments (Van den Bossche et al. 2006). These two team learning processes, through which the shared mental model is built, are elaborated on below.

Towards mutual understanding: construction and co-construction of meaning

The process of building a shared conception of a problem or situation starts with the articulation of personal meaning in the social setting (Beers et al. 2007). This process starts when one of the team members inserts meaning by describing the problem situation and how to deal with it, hereby tuning in to fellow team-members. These fellow team-members are actively listening and trying to grasp the given explanation by using this understanding to give meaning to the situation at hand (Webb and Palincsar 1996). We refer to these processes as construction of meaning.

Processes of construction of meaning can evolve into collaborative construction (i.e., co-construction), which is a mutual process of building meaning by refining, building on, or modifying the original offer in some way (Baker 1994). The outcome of this process is that 'new' meanings, which were not previously available to the group, emerge in the collaborative work. 
Towards mutual agreement: constructive conflict

Shared mental models are developed when agreement is reached around the (co-)constructed understandings. It is not sufficient that the inserted meanings are clarified and that there is mutual understanding. They must also be accepted before they form the basis for action (Alpay et al. 1998). If accepted, the offered meaning can become part of the common ground which is the agreed-upon interpretation of the situation. However, the team members may diverge in their interpretation and tackle the situation from another point of view or perspective. This rejection of the built understanding can lead to a further elaboration of the different meanings. However, it is argued that the emergence of differences in opinion does not guarantee conceptual advancement because it may be taken as a paradox, and resolved by ignoring one of the conflicting elements (De Dreu and Weingart 2003). Another argument is it may not be seen as a difference in the interpretation of the problem, but as a personal, emotional rejection and can as such interfere with productive team behavior (De Dreu and Weingart 2003). So, disagreement or divergence in itself seems to be less important than the fact that it generates communication between peer members (Dillenbourg et al. 1996). The team will only benefit if divergence in meaning leads to deep-level processing of the diverse information and viewpoints in the team (van Knippenberg et al. 2004; Homan et al. 2007). An open-minded discussion of diverse views is a critical social process by which a more complete awareness and appreciation of the complexity of the problem at hand is developed, incorporating the diverse ideas (Tjosvold et al. 2004; Tjosvold 2008). Through this negotiation by argument and clarification, the team works towards a convergence of meaning in order to reach shared mental models. Therefore, we define constructive conflict as dealing with differences in interpretation between team members by arguments and clarifications.

This framework leads to the following hypotheses. First, it is hypothesized that a higher frequency of processes as (co-)construction and constructive conflict in the interaction of the team will positively influence the level of shared task mental models (H1). Second, it is hypothesized that teams with greater levels of shared task mental models will be more effective than teams with lower levels of shared task mental models (H2). This leads to the third hypothesis that the team learning behaviors (co-)construction and constructive conflict will influence team effectiveness through the development of shared mental models (i.e., a mediator) (H3). These hypotheses can be summarized in the model presented in Fig. 1 .

\section{Measurement of shared mental models}

Within the learning sciences only few studies have tried to directly measure shared mental models (e.g., Jeong and Chi 2007; Fischer and Mandl 2005; Beers et al. 2007). In most research shared cognition is 'deduced' from the interaction in teams. Jeong and Chi have pointed out the limitation of such an approach. Team research in organization sciences, on the other hand, provides more examples of measuring shared mental models or similar constructs. Nevertheless, many authors have pointed to the problematic issue of the measurement of shared mental models (e.g., Weinberger et al. 2007; Cannon-Bowers and Salas 2001; Mohammed and Dumville 2001). Researchers used many methods, each of them having strengths and weaknesses.

Selecting a group-level cognitive structure measurement technique must begin with a clear specification of the phenomenon to be tested and modeled (Mohammed et al. 2000). 
We have conceptualized shared mental models as team members' overlapping mental representation of key elements of the team's task environment. It is stressed that a mental model can be seen as a knowledge structure, indicating that it contains both concepts and relations between those elements. This means that our measurement technique must deal with both, what Mohammed et al. call elicitation and representation to uncover the convergence of the team members' mental models. Elicitation refers to the technique used to determine the components or content of a mental model. Representation refers to the technique used to reveal the structure, the relationships between elements in the mental model. This is crucial, because meaning is affected by the use of concepts in their context.

Mohammed et al. (2000) reviewed a range of promising methods for shared mental model research dealing with both content and structure, such as pathfinder, multi-dimensional scaling, card sorting, and cognitive mapping. In making a deliberate choice, it is important to consider how one wants to deal with the measurement issues elicitation and representation, taking into account the situation and the constructs one wants to draw conclusions about.

Regarding elicitation, measurement methods vary with regard to whether the cognitive content information is supplied by the researcher or is directly requested from the participants. In the former, the comparison of the individual's mental model is facilitated. In contrast, the latter, where the content is requested from the participants, captures the idiosyncratic content of the knowledge structure of an individual. Richer data are generated through the second kind of elicitation (Cooke 1994). For this reason, we chose to rely on a methodology that depends on an open exploration of the participants' mental model of the participants, namely cognitive mapping methodologies. These methodologies deliver representations of both the content and structure of individuals' idiosyncratic belief systems in a particular domain (Mohammed et al. 2000). Cognitive mapping is used extensively by researchers of organizational behavior, strategic management, and political science (e.g., Axelrod 1976; Eden 1988). Cognitive mapping as methodology includes a diversity of elicitation techniques (interactively requesting the data from participants through interviews or through post hoc analysis of data like texts). We considered techniques that elicit as much information as possible, with a non-intrusive, extensive datacollection method. This led us to the cognitive mapping based on texts. Such text-based cognitive mapping is based on non-invasive and non-reactive data collection, avoiding recall biases of interviews (Axelrod 1976). Texts contain a portion of the author's mental model at the time the text was created (Kaufer and Carley 1993).

Carley's (1997) research delivered the methodology of text-based cognitive mapping for assessing shared mental models. She collected evidence on the reliability and validity of the method, which showed to be satisfactory.

\section{Method of Carley ${ }^{1}$}

Carley (1997) presented and explored an automated approach for extracting a map representing individual's mental model from a text, analyzing it, and combining the individual's mental models to a representation of the team mental model. In this approach, texts are first coded as networks of concepts representing individual mental models. To this end, the concepts (i.e., a single ideational category) that appear in the text are identified. This is achieved through a process of filtering in which is decided how concepts of the texts

\footnotetext{
${ }^{1}$ For a more thorough description of this method and literature on the methodological and theoretical underpinnings, we refer to Carley (1997).
} 
are to be coded. The researcher determines whether all words in the text are used or whether some will be deleted. Further, she or he also decides whether to use the exact words in the text, or whether certain words will be generalized using a thesaurus. Next, relationships between concepts are identified. Different authors have made different conceptualizations of these relationships (e.g., Axelrod 1976). Carley (1997) however argues that in all these conceptualizations the pattern of relations is of importance, and that only those concepts are related that are physically proximal. This means that the researcher has to decide how proximally distant concepts can be from each other and still have a relationship (windowing). The identified concepts and relations between them give rise to statements. The combinations of these statements form the mental model.

After coding the individual mental models, the shared mental model of the team is derived. This entails that the representation of individual mental models are combined to form a representation of the team mental model. The intersection of the different maps of the team members is also a map and can be seen as a representation of the shared mental model. Automap also supports this procedure (Diesner and Carley 2004; Carley 1997).

\section{Method}

\section{Participants}

The subjects were 81 first-year bachelor students in an International Business Economics degree program, following a skills training for 2 weeks at the end of the first year. The mean age of the participants was 21 years and 6 months ( $\mathrm{SD}=2$ years), 27.2\% was female and $47 \%$ of the participants were Dutch, $36 \%$ German and the rest of different western countries. They were divided randomly into 27 teams of three voluntary students. Participants received a small gift.

Task

Teams were confronted with the business simulation game "Steer the Economy", developed by Woltjer (2005), which simulates a business-economic system. Teams of players represent the management of different companies and make their company's decisions. Team members interacted face-to-face. All companies playing the game are interlinked through a computer network. The cumulative efforts of each team represent the general economy's movements. The macro-economy consists of four markets: a market for consumption goods, a labor market, a market for investment goods and a credit market. There are five main types of actors: companies, consumers, employees, banks and governments. The computer model simulates the decisions of the consumers, employees, banks and governments. The mission of the companies is to maximize the value of their companies by the end of the game. This value consists of equity, which is the sum of equity at the start of the game plus all retained profits during the game, and 'goodwill', which is an estimate of the net present value of future profits (Woltjer 2005).

This task was chosen because of its authenticity: management teams, confronted with a fast changing and complex environment, are required to make management decisions. An overwhelming amount of authentic data on the economy and the company itself is available. Teams have to decide on the information relevant for their decisions. Due to the complexity and the amount of available information, the team members are interdependent 
in dealing with the task. The success is dependent of the integration of different perspectives on the importance of the available information.

\section{Procedure}

The business simulation game "Steer the Economy" is part of the skills-training program within the first year of an International Business Economics degree program. The course is composed out of two cycles (each cycle takes 1 week). In the first cycle the teams have the opportunity to get acquainted with the technology and can explore the game. In the second cycle, the teams play the game with the goal of maximizing the value of their company.

Data on the mental models and the performance were collected in week two at the end of the first $2 \mathrm{~h}$ of the second cycle. In these $2 \mathrm{~h}$ the students had managed their company for a simulated period of circa 8 years. Data on team learning behaviors were collected with regard to both cycle 1 and cycle 2 .

\section{Measures}

\section{Team learning behaviors}

The three aforementioned aspects of the team learning behaviour (construction, coconstruction, and constructive conflict) were questioned by nine items (Van den Bossche et al. 2006, see Appendix 1). A confirmatory factor analysis showed that the three aspects of team learning behavior were discernable in the questionnaire. ${ }^{2}$ One item ('In this team, I share all relevant information and ideas I have') was changed from the first dimension to the constructive conflict-dimension based on this analysis $\left(\chi^{2}=21.08\right.$; $\mathrm{df}=24 ; p=0.63$; RMSEA $=0.00 ; \mathrm{NNFI}=0.99 ; \mathrm{CFI}=1.0)$. Importantly, this three factor solution provides a better fit than a 1 -factor solution $\left(\chi^{2}=34.94\right.$; $\mathrm{df}=27$; $p=0.14 ; \mathrm{RMSEA}=0.104 ; \mathrm{NNFI}=0.95 ; \mathrm{CFI}=0.96$ ).

\section{Shared mental model of the team}

Data on team members' mental model was collected through two open-ended questions. These questions asked for both declarative and procedural knowledge on the management of the company in the economy game ("Which variables in the game do you think are important to consider playing this economy game? and In which way do you think these variables influence the success or failure of your company?").

The procedure described earlier was used to extract the map representing the individual mental model. During coding, two important steps are taken: filtering and windowing. When the texts are filtered, words are deleted and generalized. This was based on a delete list and a thesaurus. The delete list contained all words not contributing to the question (articles, conjunctions, etc.) and words that indicated the relation between concepts (leading to, causing, etc.). The thesaurus contained two types of generalization: concepts which in this context had similar meaning were taken as the same concept and concepts with the same base but different endings were recoded as the same concept (e.g., market and markets both became market). Examples of concepts are labour, demand, machine, and profit. Both lists were made by an individual experienced with the game and were based on

\footnotetext{
${ }^{2}$ Results of confirmatory factor analysis with the item in the original expected scale: $\chi 2=31.74$, $\mathrm{df}=24$, $p=0.31 ; \mathrm{RMSEA}=0.066 ; \mathrm{NNFI}=0.95 ; \mathrm{CFI}=0.97$.
} 
all the texts of the participants. The window size was put at eight (Carley 1997), which means that relations were identified in a range of eight concepts, without taking into consideration the deleted items. This resulted in individual maps of the team members, which were the input for the computation of the shared mental models.

Shared mental models (team maps) were identified as containing those concepts and statements that were identical in at least two out of three individual's cognitive maps (i.e., a lossy intersection rule, Carley 1997). Two measures were computed in order to get a quantitative measure for the sharedness of the mental model: The number of concepts that were identical in at least two out of three individual's cognitive maps and the number of statements (two concepts and their relation) that were identical in at least two out of three individual's cognitive maps. As described, statements would reflect more profound the meaning of the knowledge elements (Carley 1997). Therefore, it was expected that the measurement by the statements would more closely reflect the true shared mental model.

\section{Team effectiveness}

\section{Perceived team effectiveness}

A broad approach to effectiveness was taken to include the multiplicity of outcomes that matter in organizational settings (Hackman 1989). Not only is the degree to which the team output meets the standard of quality (team performance) of importance, but also the degree to which the process of carrying out the work enhances the capability of members to work together in the future (team viability), and the degree to which the team work contributes to the professional growth of the team members (team learning). These dimensions were questioned using three items (Van den Bossche et al. 2006). A confirmatory factor analyses showed that these items belonged to one factor, independent from the three factors constituting team learning behaviour $\left(\chi^{2}=45.20 ; \mathrm{df}=48 ; p=0.59 ; \mathrm{RMSEA}=0.00\right.$; $\mathrm{NNFI}=0.97$; $\mathrm{CFI}=0.98$ ).

\section{Actual team performance}

In addition to assessing the perception of the team effectiveness by the team members, we also collected data on the actual performance of the company they were managing in the game. Mean equity and goodwill in the last year (of the 8 years the game lasted) were taken as measures of actual team performance.

\section{Aggregation on team level}

The constructs measured in the survey (team learning behaviours and perceived team performance) are conceptually meaningful at the team-level. Therefore, the data gathered from individual team members to assess these team-level variables were aggregated at the team level. The within-group agreement was assessed using the multiple-item estimator $r_{\mathrm{wg}}$ (James et al. 1984). This analysis resulted in a mean value of 0.89 for construction, 0.90 for co-construction 0.91 for constructive conflict, and 0.93 for team effectiveness. These results justify the creation of a group-level data-set. Descriptive statistics (mean and standard deviation), the intercorrelations and the internal consistency of the scales at the team-level of analysis are presented in Table 1. 
Table 1 Means, standard deviations and intercorrelations (alpha-coefficients for the questionnaire are given on the diagonal)

\begin{tabular}{lllllllll}
\hline Variable & 1 & 2 & 3 & 4 & 5 & 6 & 7 & 8 \\
\hline 1. Construction & 0.84 & & & & & & \\
2. Co-construction & $0.77^{* * *}$ & 0.84 & & & & & \\
3. Constr. conflict & $0.60^{* *}$ & $0.69^{* *}$ & 0.83 & & & & \\
4. SMM-conc & 0.16 & -0.06 & 0.31 & - & & & & \\
5. SMM-stat & 0.11 & -0.15 & 0.21 & $0.91^{* *}$ & - & & & \\
6. Perceived team performance & $0.42^{*}$ & $0.46^{*}$ & $0.75^{* *}$ & 0.28 & 0.16 & 0.83 & & \\
7. Actual team performance: & 0.21 & 0.20 & 0.28 & $0.51^{* *}$ & $0.43^{*}$ & 0.32 & - & \\
$\quad$ equity & & & & & & & & \\
8. Actual team performance: & -0.21 & -0.27 & 0.07 & $0.50^{* *}$ & $0.50^{* * *}$ & 0.20 & $0.41^{*}$ & - \\
$\quad$ goodwill & & & & & & & & \\
Mean & 6.00 & 5.73 & 5.72 & 6.00 & 10.18 & 5.99 & 10128539.6 & 9477871.8 \\
S.d. & 0.61 & 0.59 & 0.53 & 2.41 & 10.51 & 0.64 & 20343459.6 & 6965830.3 \\
\hline
\end{tabular}

Sign 2-tailed: * significant at the 0.05 level $/ * *$ significant at the 0.01 level

SMM-conc number of concepts shared by 2 or 3 members of the team, SMM-stat number of statements shared by 2 or 3 members of the team

\section{Results}

The results are presented in the two following sections. The first section deals with the hypothesized influence of team learning behaviors on the development of a shared mental model (H1). The second section presents analyses testing the hypothesized relation between shared mental models in teams and team performance (H2). This is followed by an examination of shared mental models as mediator of the relationship between team learning behaviors and team effectiveness (H3).

Team learning behaviors and shared mental models

It was hypothesized that team learning behaviors would influence the development of shared mental models (H1). Two multiple regression analyses were conducted to test this hypothesis. In these analyses, the two indicators of shared mental model (shared concepts and shared statements) were regressed onto the three identified team learning behaviors (construction, co-construction and constructive conflict).

The results presented in Table 2 show that the identified learning behaviors significantly influence the development of a shared mental model of the task in a team. The results for both indicators of shared mental models, shared concepts and shared statements, are very similar. The team learning behaviors co-construction and constructive conflict contribute to the development of a shared mental model in the team. However, these results show that, contrary to the expectations, the co-construction behavior of the team does not contribute to the development of shared mental models. In fact, the unique effect of co-construction is negatively connected to the sharedness of mental models. The intercorrelation of the variables co-construction and shared mental model (indicated by sharing of concepts and statements) as presented in Table 1 is close to zero. The regression learns that if we also take into consideration the construction and constructive conflict behavior, the singular effect of co-construction behaviors becomes negative. 
Table 2 Regression analysis team learning behaviors predicting shared mental model

Standardized beta coefficients are reported

* Significant at the 0.05 level/

** significant at the 0.01 level

\begin{tabular}{lcc}
\hline & SMM-conc & SMM-stat \\
\hline Construction & 0.39 & 0.45 \\
Co-construction & $-0.78^{*}$ & $-0.86^{* *}$ \\
Constructive conflict & $0.62^{*}$ & $0.53^{*}$ \\
$R^{2}$ & 0.30 & 0.29 \\
Adjusted $R^{2}$ & 0.21 & 0.20 \\
$F$ & 3.283 & 3.146 \\
Sign & 0.039 & 0.045 \\
\hline
\end{tabular}

Table 3 Regression analysis shared mental models predicting team performance

\begin{tabular}{|c|c|c|c|c|c|c|c|c|c|}
\hline & \multicolumn{3}{|c|}{$\begin{array}{l}\text { Perceived team } \\
\text { performance }\end{array}$} & \multicolumn{3}{|c|}{$\begin{array}{l}\text { Actual team performance } \\
\text { equity }\end{array}$} & \multicolumn{3}{|c|}{$\begin{array}{l}\text { Actual team performance } \\
\text { goodwill }\end{array}$} \\
\hline & Beta & Adj $R^{2}$ & $F($ sign $)$ & Beta & $\operatorname{Adj} R^{2}$ & $F($ sign $)$ & Beta & $\operatorname{Adj} R^{2}$ & $F($ sign $)$ \\
\hline SMM-conc & 0.28 & 0.08 & $2.08(0.16)$ & $0.51 * *$ & 0.23 & $8.62(0.007)$ & $0.50 * *$ & 0.22 & $8.48(0.007)$ \\
\hline SMM-stat & 0.16 & 0.00 & $0.67(0.42)$ & $0.43^{*}$ & 0.15 & $5.59(0.026)$ & $0.50 * *$ & 0.22 & $8.45(0.008)$ \\
\hline
\end{tabular}

Standardized beta coefficients are reported

* Significant at the 0.05 level/** significant at the 0.01 level

Shared mental models and team effectiveness

To test the relation between shared mental models in teams and team effectiveness (H2) regression analysis of the two indicators of shared mental models onto the different criteria of team performance are conducted. Results of these analyses are presented in Table 3.

The results indicate a significant and important relation between the two indicators of shared mental models and the results of the company managed by the team in the economy game. Sharing concepts in the team is linked with both the equity results (Beta $=0.51$, $p=0.007$ ) and the goodwill (Beta $=0.50, p=0.007$ ), as well as the number of shared statements is positively linked with both equity (Beta $=0.43, p=0.026$ ) and goodwill (Beta $=0.50, p=0.008$ ) of the company. No significant link is observable between the developed shared mental model and the team performance as perceived by the team itself; both for the indicator shared concepts $($ Beta $=0.28$; n.s.) and for the indicator shared statements (Beta $=0.16$; n.s.).

\section{Mediation}

Additional analyses were conducted to examine whether shared mental model fully mediate the influence of team learning behavior on team effectiveness (H3). These analyses were informed by a procedure suggested by Baron and Kenny (1986). The analyses already described have established that team learning behaviors account for significant variance in shared mental model (i.e., the mediator). Also it is shown that the level of shared mental model is significantly related to actual team performance. However no relation is found between the developed shared mental model and the perceived team performance.

To test for mediation, two more regression equations should be estimated (Baron and Kenny 1986). The first tests whether team learning behavior accounts for significant variance 
in team effectiveness (perceived and actual). Results from stepwise multiple regression analyses indicate that team learning behaviors account for variability in actual team performance indicator goodwill $\left(R^{2}=0.20, F(2.24)=3.002, p=0.069 ; \beta_{\text {co-construction }}=\right.$ $\left.-61, p=0.02 ; \beta_{\text {constructive conflict }}=0.48, p=0.06\right)$ and perceived team performance $\left(R^{2}=0.56, F(3.23)=9.734, p=0.00 ; \beta_{\text {construction }}=0.03, \mathrm{~ns} ; \beta_{\text {co-construction }}=-12, \mathrm{~ns}\right.$; $\left.\beta_{\text {constructive conflict }}=0.81, p=0.00\right)$. But it does not for the actual team performance indicator equity $\left(R^{2}=0.08, F(1.25)=2.074, p=0.16\right)$. Finally, the team learning behaviors were entered in the regression equation after controlling for the level of shared mental model. On the condition that relations are established in the previous regression analyses, if team learning behaviors fail to account for significant incremental variance, the evidence is consistent with full mediation of shared mental model. Adding the team learning behaviors to the equation in which equity was regressed on the level of shared mental model failed to account for significant additional variance for both indices of shared mental models (shared concepts, $\Delta R^{2}=0.063, p=0.57$; shared statements, $\Delta R^{2}=0.075, p=0.54$ ). Similar results were obtained when team learning behaviors were added to the equation in which goodwill was the dependent variable, also for both indices of shared mental models (shared concepts, $\Delta R^{2}=0.063, p=0.57$; shared statements, $\Delta R^{2}=0.075, p=0.54$ ). The preconditions for shared mental model mediating the effect of team learning behaviors on perceived team effectiveness are not met. Due to this no further test of mediation is meaningful.

To summarize, these analyses give substantial support for the idea that the effect of team learning behaviors on the actual team performance is mediated by the development of a shared mental model. For goodwill as a dependent variable, all conditions were met. In the case of equity as a dependent variable all conditions were not met. Whereas team learning behaviors do not show any significant relationship with equity, they did have a positive influence on the level of shared mental model, which in turn are significantly related to performance. These results are strongly indicative of an indirect effect (see Appendix 2). Contrary to these findings, the results of these analyses suggest that the effect of team learning behaviors on perceived team effectiveness are not mediated by the development of a shared mental model.

\section{Conclusions and discussion}

This study sought to determine those team learning behaviors which lead to the construction of a shared mental model, leading to increased team performance.

Team learning behaviors and shared mental model

The findings of this study support the premise that team learning behaviors are related to the development of a shared mental model (H1). However, the relation appears to be more complex than initially hypothesized. Constructive conflict was found to be a significant behavior in the process of building shared mental model. On the other hand, the team behaviors conceptualized as co-construction do not in themselves contribute to the development of shared mental models. The findings actually show that they even hinder this development. Although this is not in line with our hypothesis, it strengthens the theoretical assertion that for the development of shared mental models both mutual understanding and mutual agreement are necessary (Baker 1995, 1999). These results suggest that mere co-construction behavior (complementing each other information and 
ideas) is not enough. This corresponds with the observations of Jeong and Chi (2007) regarding the challenges in reaching shared cognition. They pointed out that it is probably not sufficient to simply pay attention and acknowledge a contribution; an active effort to integrate the contribution in the existing representation is needed. The mental models of these teams are probably only 'shared' as distributed and not 'shared' as agreed upon. Our results seem indeed to indicate that teams merely engaging in co-construction probably do not negotiate their knowledge and therefore only develop increasingly different mental models.

The role of constructive conflict is critical: only if there is a critical stance regarding each others contributions, if there is thorough consideration of each other ideas and comments, and if team members address differences in opinion and can speak freely, will there be really construction of a shared mental model. If this behavior is lacking, team learning is not taking place (Van Knippenberg et al. 2004). Showing constructive conflict behavior reflects a true engagement in reaching a shared view on the topic.

This research goes beyond previous findings by identifying the kind of interactions that can be considered as team learning behavior leading to the development of shared mental models. Hereby, this research extends previous team learning research by establishing a relation between team learning behavior and the level of shared mental model (Jehn and Rupert 2007).

\section{Shared mental model and team-work}

We hypothesized that teams with greater levels of shared task mental models will be more effective (H2). It indeed showed that the results of a "company" improved if the studentmanagement team has developed a higher level of shared mental model. This evidence supports the assertion of the importance of group sense-making: effective teams are able to build a shared conception of the problem at hand (Dillenbourg et al. 1996; Roschelle 1992). These results add to similar findings that indicate that shared mental models are related to important team outcomes (e.g., Mathieu et al. 2000, 2005).

With regard to the third hypothesis, this study shows that the development of a shared mental model in a team through team learning behaviors results in better team performance. However, the results showed that team effectiveness, as perceived by the team members, is related differently to the level of shared mental model of the team than is the actual performance. The relation between team learning behaviors and team effectiveness was not mediated by the level of shared mental model of the team. In evaluating this result, we must take into account that the team performance as studied in the survey is broadly conceptualized (Hackman 1989). It not only contains team performance, but also considers effects on the development of the team and the team viability. Other mental models should probably be considered (e.g., mental model of the team or the team interaction) to get a better understanding of the relation between shared mental models and these different aspects of team effectiveness.

It is remarkable that no substantial differences were found between the analyses based on either the numbers of concepts shared or the number of statements shared as indicator of the shared mental model of the team. It was expected that the statements would better reflect the shared mental model, since this measurement grasps the structure of the knowledge and thus reflects more the meaning of the knowledge elements (Mohammed et al. 2000; Carley 1997). This suggests that if concepts were shared, they mostly had the same meaning and thus were part of the same knowledge structure. On the other hand, this could also be partially a consequence of using the 'windowing technique'. This automated 
approach based on physical proximity can be prone to accidental relation. More research is necessary to understand the consequences of choices with regard to filtering and windowing (Carley 1997).

\section{Limitations, future research and practical implications}

This article underscores the importance of developing shared cognition in teamwork. However, shared cognitions are not necessarily accurate once (Mathieu et al. 2005; Cannon-Bowers and Salas 2001). Examining the quality of the mental models shared by the team members would provide more insight in the relation of shared mental models and performance and the role of team learning behaviors in this. However, this is challenging for examining team shared mental models in the context of dealing with complex problems, as heterogeneous accurate mental models are available in these kind of situations. Future research should test methodologies dealing with the unavailability of one expert model (Mathieu et al. 2005).

The present study is to a high extent founded on perceptions of the team-members regarding team learning behaviors. One can question how perceptions of the team learning behaviors are related to the concrete behaviors of team members. Although consistency is found between the self-reported learning behaviors and the learning behaviors as reported by an external observer (Edmondson 1999), it would be worthwhile to have observations of these behaviors.

Also, it needs to be taken into account that the teams in this research were composed out of students, confronted with a simulation game for only 2 weeks. Simply generalizing these findings to real project teams is not appropriate. Further research is needed to validate these findings in other settings.

This research and the underlying conceptual framework can and need to be a first stepping stone to build a multi-level perspective on team learning, integrating the individual level and the influences by the context (Kozlowski and Klein 2000). On the one hand by questioning how this team level is linked with the lower individual level (the characteristics of the team members and the learning that is occurring at that level). And on the other hand by examining how this is influenced by the context (formed by the task and group type and broader environmental factors).

Moreover, the results of the present research suggest practical consequences for both students and professionals, since collaborative learning formats are frequently used in education and teamwork is omnipresent in organisations. This research sheds light on the cognitive demands of teams in dealing with the framing of the task or problem at hand; sharing knowledge is indeed crucial for increasing the effectiveness of teams. To achieve this, these teams will have to pay explicit attention to their socio-cognitive processes in order to promote team learning as an avenue to develop shared mental models. The results underline the power of disagreement or conflict (Jehn 1994), but even more they stress the potential and need of dealing constructively with different opinions that may arise in a team. Differences of opinion need to be seen as windows of opportunity instead of threats to progress. Previous research has shown that an interpersonal context characterised by, for example, psychological safety (Edmondson 1999; Van den Bossche et al. 2006) can foster these learning behaviors. This stresses the need for the management of both social and cognitive processes in teams. Team members can be trained to monitor and strengthen their internal functioning. Proficiency in the skills of team discussion is an important building block: being willing to express ideas and positions, ask each other for more information and arguments and integrate ideas (Tjosvold et al. 2004). 
Acknowledgment This research was supported by a grant from the Dutch Institute of Scientific Research (NWO), grant number 014-43-704.

Open Access This article is distributed under the terms of the Creative Commons Attribution Noncommercial License which permits any noncommercial use, distribution, and reproduction in any medium, provided the original author(s) and source are credited.

\section{Appendix 1: items, factor and loading}

Team learning behaviors

1. In this team, I share all relevant information and ideas I have (constructive conflict, $0.77)$.

2. Team members are listening carefully to each other (construction, 0.78).

3. If something is unclear, we ask each other questions (construction, 0.92).

4. Team members elaborate on each other's information and ideas (co-construction, $0.74)$.

5. Information from team members is complemented with information from other team members (co-construction, 0.77).

6. Team members draw conclusions from the ideas that are discussed in the team (coconstruction, 0.90).

7. This team tends to handle differences of opinions by addressing them directly (constructive conflict, 0.81).

8. Comments on ideas are acted upon (constructive conflict, 0.70).

9. Opinions and ideas of team members are verified by asking each other critical questions (constructive conflict, 0.71).

Team effectiveness

10. I am satisfied with the performance of our team (team effectiveness, 0.74).

11. I would want to work with this team in the future (team effectiveness, 0.96).

12. As a team, we have learned a lot (team effectiveness, 0.72).

\section{Appendix 2}

Recently it has been suggested that step 1 (in the case of this research, the direct effect of team learning behaviors on performance) of the classic mediation analysis is not actually necessary to establish mediation (Collins et al. 1998; Shrout and Bolger 2002). The logic is that step 1 is not required, since a path from the initial variable to the outcome is implied if steps 2 and 3 are met. The emphasis is on steps 2 and 3 over step 1, since there are a variety of ways in which mediation could be occurring, but the direct relationship in step 1 still would not be significant, including causal distance, suppressor variables, and contingencies operating on the mediator itself (Langfred 2004).

The Sobel test is proposed as more appropriate to test an indirect effect (Preacher and Hayes 2004). Sobel analyses were conducted for the different dependent and mediating variables. It showed that when shared concepts are taken as mediator, an indirect effect of learning behavior on goodwill $(p=0.05)$ and on equity $(p<0.10)$ is established. Consistent results are found when shared statements are taken as mediator. This provides further evidence for shared mental models as mediator of team learning behaviors on team performance. 


\section{References}

Akkerman, S., Van den Bossche, P., Admiraal, W., Gijselaers, W., Segers, M., Simons, R.-J., et al. (2007). Reconsidering group cognition: From conceptual confusion to a boundary area between cognitive and socio-cultural perspectives? Educational Research Review, 2(1), 39-63.

Alpay, L., Giboin, A., \& Dieng, R. (1998). Accidentology: An example of problem solving by multiple agents with multiple representations. In M. W. van Someren, P. Reimann, H. P. A. Boshuizen, \& T. de Jong (Eds.), Learning with multiple representations (pp. 152-174). Amsterdam: Pergamon.

Axelrod, R. (1976). The structure of decision. Princeton, NJ: Princeton University Press.

Baker, M. (1994). A model for negotiation in teaching-learning dialogues. Journal of Artificial Intelligence in Education, 5(2), 199-254.

Baker, M. (1995). Negotiation in collaborative problem-solving dialogues. In R.-J. Beun, M. Baker, \& M. Reiner (Eds.), Dialogue and instruction. Modeling interaction in intelligent tutoring systems (pp. 39-55). Berlin: Springer-Verlag.

Baker, M. J. (1999). Argumentation and constructive interaction. In P. Coirier \& J. Andriessen (Eds.), Foundations of argumentative text processing (pp. 179-202). Amsterdam: University of Amsterdam Press.

Baron, R. M., \& Kenny, D. A. (1986). The moderator-mediator variable distinction in social psychological research: Conceptual, strategic and statistical considerations. Journal of Personality and Social Psychology, 51, 1173-1183.

Barron, B. (2000). Achieving coordination in collaborative problem-solving groups. Journal of the Learning Sciences, 9(4), 403-436.

Beers, P. J., Kirschner, P. A., Boshuizen, H. P. A., \& Gijselaers, W. (2007). ICT-support for grounding in the classroom. Instructional Science, 35, 535-556.

Cannon-Bowers, J. A., \& Salas, E. (2001). Reflections on shared cognition. Journal of Organizational Behavior, 22, 195-202.

Cannon-Bowers, J. A., Salas, E., \& Converse, S. (1993). Shared mental models in expert team decision making. In N. J. Castellan (Ed.), Individual and group decision making: Current issues. Hillsdale, New Jersey: Lawrence Erlbaum Associates.

Carley, K. M. (1997). Extracting team mental models through textual analysis. Journal of Organizational Behavior, 18, 533-558.

Collins, L. M., Graham, J. W., \& Flaherty, B. P. (1998). An alternative framework for defining mediation. Multivariate Behavioral Research, 33, 295-312.

Cooke, N. J. (1994). Varieties of knowledge elicitation techniques. International Journal Human-Computer Studies, 41, 801-849.

Crook, C. (1998). Children as computer users: The case of collaborative learning. Computers and Education, 30(3/4), 237-247.

De Dreu, C. K. W., \& Weingart, L. R. (2003). Task versus relationship conflict, team performance, and team member satisfaction: A meta-analysis. Journal of Applied Psychology, 88(4), 741-749.

Diesner, J., \& Carley, K. M. (2004). Automap 1.2-Extract, analyze, represent, and compare mental models from texts (Technical report CMU-ISRI-04-100). Carnegie Mellon University, School co Computer Science, Institute for Software Research International.

Dillenbourg, P., Baker, M., Blaye, A., \& O'Malley, C. (1996). The evolution of research on collaborative learning. In E. Spada \& P. Reiman (Eds.), Learning in Humans and Machine: Towards an interdisciplinary learning science (pp. 189-211). Oxford: Elsevier.

Dillenbourg, P., \& Traum, D. (2006). Sharing solutions: Persistence and grounding in multimodal collaborative problem solving. Journal of the Learning Science, 15(1), 121-151.

Eden, C. (1988). Cognitive mapping. European Journal of Operational Research, 36, 1-13.

Edmondson, W. (1981). Spoken discourse: A model for analysis. London: Langman.

Edmondson, A. C. (1999). Psychological safety and learning behavior in work teams. Administrative Science Quarterly, 44, 350-383.

Fischer, F., \& Mandl, H. (2005). Knowledge convergence in computer-supported collaborative learning: The role of external representation tools. The Journal of the Learning Sciences, 14(3), 405-441.

Hackman, J. R. (Ed.). (1989). Groups that work (and those that don't), creating conditions for effective teamwork. San Francisco: Jossey-Bass.

Homan, A. C., van Knippenberg, D., Van Kleef, G. A., \& De Dreu, C. K. W. (2007). Bridging faultlines by valuing diversity: Diversity beliefs, information elaboration, and performance in diverse work groups. Journal of Applied Psychology, 92(5), 1189-1199.

James, L. R., Demaree, R. G., \& Wolf, G. (1984). Estimating within-group interrater reliability with and without response bias. Journal of Applied Psychology, 69(1), 85-98. 
Jehn, K. A. (1994). Enhancing effectiveness: An investigation of advantages and disadvantages of valuebased intragroup conflict. International Journal of Conflict Management, 5, 223-238.

Jehn, K. A., \& Rupert, J. (2007). Group faultlines and team learning: How to benefit from different perspectives. In V. L. Sessa \& M. London (Eds.), Work group learning, Understanding, improving and assessing how groups learn in organizations. Mahwah: Lawrence Erlbaum Associates.

Jeong, H., \& Chi, M. T. H. (2007). Knowledge convergence and collaborative learning. Instructional Science, 35, 287-315.

Johnson-Laird, P. (1983). Mental models. Cambridge, MA: Harvard University Press.

Kaufer, D. S., \& Carley, K. M. (1993). Communication at a distance: The effect of print on socio-cultural organization and change. Hillsdale, NJ: Lawrence Erlbaum Associates.

Klimoski, R., \& Mohammed, S. (1994). Team mental model: Construct or metaphor? Journal of Management, 20(2), 403-437.

Kozlowski, S. W. J., \& Klein, K. J. (2000). A multilevel approach to theory and research in organizations: Contextual, temporal, and emergent processes. In K. J. Klein\& S. W. J. Kozlowski (Eds.), Multilevel theory, research, and methods in organizations: Foundations, extensions, and new directions (pp. 3-90). San Francisco: Jossey Bass.

Langfield-Smith, K. (1992). Exploring the need for a shared cognitive map. Journal of Management Studies, 29, 349-368.

Langfred, C. W. (2004). Too much of a good thing? Negative effects of high trust and individual autonomy in self-managing teams. Academy of Management Journal, 47, 385-399.

Mathieu, J. E., Heffner, T. S., Goodwin, G. F., Cannon-Bowers, J., \& Salas, E. (2005). Scaling the quality of teammates' mental models: Equifinality and normative comparisons. Journal of Organizational Behavior, 26, 37-56.

Mathieu, J. E., Heffner, T. S., Goodwin, G. F., Salas, E., \& Cannon-Bowers, J. A. (2000). The influence of shared mental models on team process and performance. Journal of Applied Psychology, 85(2), 273283.

Mohammed, S., \& Dumville, B. C. (2001). Team mental models in a team knowledge framework: Expanding theory and measurement across disciplinary boundaries. Journal of Organizational Behavior, 22, 89-106.

Mohammed, S., Klimoski, R., \& Rentsch, J. R. (2000). The measurement of team mental models: We have no shared schema. Organizational Research Methods, 3(2), 123-165.

Preacher, K. J., \& Hayes, A. F. (2004). SPSS and SAS procedures for estimating indirect effects in simple mediation models. Behavior Research Methods, Instruments, and Computers, 36, 717-731.

Rentsch, J. R. (1990). Climate and culture: Interaction and qualitative differences in organizational meanings. Journal of Applied Psychology, 75(6), 668-681.

Rentsch, J. R., \& Klimoski, R. J. (2001). Why do 'great minds' think alike? Antecedents of team member schema agreement. Journal of Organizational Behavior, 22, 107-120.

Roschelle, J. (1992). Learning by collaborating: Convergent conceptual change. Journal of the Learning Sciences, 2(3), 235-276.

Roulet, E. (1992). On the structure of conversation as negotiation. In H. Parret \& J. Verschueren (Eds.), (On) Searle on conversation. Amsterdam: John Benjamins.

Rouse, W. B., \& Morris, N. M. (1986). On looking into the black box: Prospects and limits in the search for mental models. Psychological Bulletin, 100, 359-363.

Schwartz, D. L. (1995). The emergence of abstract representations in dyad problem solving. Journal of the Learning Science, 4(3), 321-354.

Shrout, P. E., \& Bolger, N. (2002). Mediation in experimental and nonexperimental studies: New procedures and recommendations. Psychological Methods, 7, 422-445.

Stahl, G. (2006). Group cognition: Computer support for building collaborative knowledge. Cambridge, MA: MIT Press.

Thompson, L. (1998). A New look at social cognition in groups. Basic and Applied Social Psychology, 20(1), 3-5.

Thompson, L., \& Fine, G. A. (1999). Socially shared cognition, affect, and behavior: A review and integration. Personality and Social Psychology Review, 3(4), 278-302.

Tjosvold, D. (2008). The conflict-positive organization: It depends upon us. Journal of Organizational Behavior, 29, 19-28.

Tjosvold, D., Tang, M. M. L., \& West, M. (2004). Reflexivity for team innovation in China. Group and Organization Management, 29(5), 540-559.

Van den Bossche, P., Gijselaers, W., Segers, M., \& Kirschner, P. A. (2006). Social and cognitive factors driving teamwork in collaborative learning environments. Team learning beliefs and behaviors. Small Group Research, 37(5), 490-521. 
van Knippenberg, D., De Dreu, C. K. W., \& Homan, A. C. (2004). Work group diversity and group performance: An integrative model and research agenda. Journal of Applied Psychology, 89(6), 10081022.

Walsh, J. P., Henderson, C. M., \& Deighton, J. (1988). Negotiated belief structures and decision performance: An empirical investigation. Organizational Behavior and Human Decision Processes, 42, $194-$ 216.

Webb, N. M. (1991). Task related verbal interaction and mathematics learning in small groups. Journal for Research in Mathematics Education, 22, 366-389.

Webb, N. M., \& Palincsar, A. S. (1996). Group processes in the classroom. In D. C. Berliner \& R. C. Calfee (Eds.), Handbook of educational psychology. New York: Simon \& Schuster Macmillan.

Weinberger, A., Stegmann, K., \& Fischer, F. (2007). Knowledge convergence in collaborative learning: Concepts and assessment. Learning and Instruction, 17, 416-426.

Woltjer, G. (2005). Decisions and macro-economics: Development and implementation of a simulation game. Journal of Economic Education, 36(2). 